\title{
PEDAGOGIA CRÍTICO-EMANCIPATÓRIA E EDUCAÇÃO FÍSICA ESCOLAR: CONFLUÊNCIAS À MÍDIA-EDUCAÇÃO
}

\author{
CRITICAL-EMANCIPATORY PEDAGOGY AND PHYSICAL EDUCATION: \\ CONVERGENCE OF MEDIA EDUCATION
}

PEDAGOGÍA CRIITICA EMANCIPADORA Y LA EDUCACIÓN FÍSICA: LA CONVERGENCIA DE LA EDUCACIÓN EN MEDIOS

\author{
Jonatas Maia da Costa*, Ingrid Wiggers*
}

\begin{abstract}
Palavras-chave Educação.

Filosofia.

Mídia audiovisual.

Resumo: Este estudo apresenta algumas reflexões sobre a prática pedagógica da Educação Física Escolar, destacando a aproximação da pedagogia crítico-emancipatória à concepção de mídia-educação. Após breves considerações bibliográficas, 0 texto enfatiza as possibilidades de se estabelecer nexos entre as estruturas conceituais dessas duas teorias pedagógicas. Na sequência, descreve sinteticamente uma experiência pedagógica de ensino com aportes da mídia-educação. Defende a necessidade de elaboração de propostas que promovam ações pedagógicas baseadas nessas teorias, de forma que estas experiências sejam objeto de sistematizações por meio de investigações científicas no campo da escola.
\end{abstract}

Keywords

Education.

Philosophy.

Audiovisual media.

Palabras clave

Educación.

Filosofía.

Medios

audiovisuales.

Abstract: This paper presents some reflections on the pedagogical practice of Physical Education, highlighting the approximation of critical-emancipatory pedagogy to the view of media-education. After brief bibliographic considerations, the text emphasizes the possibilities of establishing links between the conceptual structures of those two pedagogical theories. Then it concisely describes a pedagogical teaching experience with contributions of media education. This text advocates the need for developing proposals that promote educational activities based on those theories, so that those experiences are systematized through scientific investigations in the school field.

Resumen: Este estudio presenta algunas reflexiones sobre la práctica pedagógica de la Educación Física Escolar, destacando la aproximación de la pedagogía crítica emancipadora a la educación en medios. Después de breves consideraciones bibliográficas, el texto hace hincapié en las posibilidades de establecer nexos entre las estructuras conceptuales de estas dos teorías pedagógicas. Se describe sintéticamente una experiencia pedagógica de enseñanza con aportes de la educación en medios. Defiende la necesidad de desarrollar propuestas que promuevan acciones pedagógicas basadas en estas teorías, de forma que estas experiencias sean objeto de sistematizaciones a través de investigaciones científicas en el campo de la escuela.
* Universidade de Brasília - UnB. Brasília, DF, Brasil.

E-mail: jonatascosta@unb.br

Recebido em: 24-05-2015 Aprovado em: 06-08-2015 (c) (i) () Licence 


\section{INTRODUÇÃO}

Ao longo dos últimos trinta anos, a Educação Física acumulou largo conhecimento de cunho didático-metodológico no que diz respeito à sua prática pedagógica na escola, tornando possível categorizar determinadas abordagens pedagógicas caracterizadas por concepções de educação e pressupostos epistemológicos (GHIRALDELLI JR, 1989; CASTELLANI FILHO, 1998; DARIDO, 2003). Tais classificações identificam, sobretudo, elementos constituintes de uma prática ${ }^{1}$ que almeja atender aos anseios do componente curricular de Educação Física na escola brasileira. De todo modo, é imperativo salientar que uma abordagem só faz sentido quando a sua sistematização teórica se submete ao crivo da escola. Caso contrário, ela corre o risco de se perder em mera especulação científica ou em complexas teorizações abstratas.

Nesse sentido, urge pensar a pedagogia crítico-emancipatória (KUNZ, 1994) no tocante aos inúmeros esforços de apresentar sistematizações metodológicas que estabelecem deliberadamente nexos entre a teoria e a sua concretização no espaço das aulas de Educação Física, como pode ser constatado em algumas publicações (KUNZ, 1998, 2002, 2003). A favor deste entendimento concorre a ideia de valorizar ações que diminuam o hiato entre os "professores que pesquisam" e os "professores que ensinam", tensionando, desta forma, o modelo tradicional de produção de conhecimento, mormente o do saber pedagógico.

Outro aspecto importante e que conota uma característica articuladora à pedagogia crítico-emancipatória tem a ver com algumas experiências investigativas que a sincretizaram a outros constructos pedagógicos e filosóficos. Isto pode ser visto em vários estudos. Falcão (1998), ao pensar a capoeira pelo viés da pedagogia crítico-emancipatória, alinha as sistematizações pedagógicas aos aspectos da ludicidade a partir das contribuições de Huizinga ${ }^{3} \mathrm{e}$ declara o jogo como um elemento de composição essencial dessa prática corporal. Cardoso (1998) apresenta uma experiência em aulas de Educação Física integrando aspectos da "concepção de aulas abertas" (HILDEBRANDT; LAGING, 1986) com as percepções da pedagogia crítico-emancipatória à guisa de contrapor a forma tradicional em que 0 esporte é tematizado para alunos da escola básica, quando geralmente se adotam princípios que favorecem a sobrepujança, a comparação objetiva, a tendência à seleção, à especialização e à instrumentalização. Matiello Jr. (2002) associou as orientações da Organização do Currículo por Projetos de Trabalho (HERNANDEZ; VENTURA, 1998) às proposições de Kunz (1994) naquilo que concerne à ênfase de dar significado às atividades escolares, na defesa de que aos alunos cabe estudar/refletir os conhecimentos da Educação Física e não apenas praticálos. Mais recentemente, Araújo et al. (2010) analisaram o eixo epistemológico fundamental da pedagogia crítico-emancipatória, traduzido por Kunz (1994) pela ideia do "se-movimentar", que, balizada pela fenomenologia, projeta o sentido de que a conduta dos sujeitos (da prática) "deve ser analisada como um acontecimento relacional numa referência situacional-pessoal" (ARAÚJO et al., 2010, p.2).

1 Vale ressaltar que as abordagens pedagógicas categorizadas pelos autores citados não compreendem em sua totalidade elementos de uma prática metodológica concreta. Castellani Filho (1992), por exemplo, classifica as abordagens em "propositivas" e "não-propositivas". Darido (2001) prefere explicitar de maneira mais ampla as abordagens pedagógicas, identificando-as desta forma: abordagem desenvolvimentista, construtivista-interacionista, crítico-superadora, crítico-emancipatória, sistêmica, cultural, psicomotricidade, saúde renovada, PCNs, jogos cooperativos.

2 Há de se perceber que esta fragmentação funcional do labor docente se estabelece pelas condições objetivas nas quais estão inseridos tanto os professores universitários como os professores da educação básica no mundo do trabalho. 
Na esteira dessas percepções surge o escopo deste trabalho. No caso, almeja-se discutir as proximidades entre a pedagogia crítico-emancipatória e 0 universo das representações midiáticas, especialmente ao entendimento da mídia-educação como proposição teórica suplementar ao ensino de Educação Física na escola com vistas à concretização de uma prática que favoreça a autonomia e a emancipação discente.

Primeiramente, apresentam-se algumas considerações teóricas da pedagogia crítico-emancipatória e da concepção de mídia-educação. A seguir, discute-se, a partir de uma experiência investigativa na escola, a articulação entre essas teorias e como é possível estabelecer conexões entre as ações pedagógicas e a busca por um ensino com características emancipatórias. Desta forma, advoga-se a necessidade de avançar em torno de propostas pedagógicas que exortem a participação discente de forma protagonista, tomando as contribuições das tecnologias de informação e comunicação como sustentáculos da didática em Educação Física. Por fim, destaca a premente necessidade de avançar os estudos da prática pedagógica por meio de investigações científicas na escola.

\section{A PEDAGOGIA CRÍTICO-EMANCIPATÓRIA E A MÍDIA-EDUCAÇÃO}

São as idiossincrasias das teorias pedagógicas que tornam os conhecimentos elaborados no contexto da escola passíveis de ser interpretados das mais diferentes formas. Realizar um recorte pontual especificamente sobre uma teoria é um trabalho audacioso, às vezes arrogante, sobretudo quando não se dispõe de espaço suficiente para dar conta de suas especificidades, como é o caso do presente trabalho. De todo modo, é necessário minimamente contextualizar conceitualmente a pedagogia crítico-emancipatória e a mídia-educação, com o intuito de clarificar os apontamentos articuladores entre as duas teorias e suas possibilidades propositivas ao ensino da Educação Física na escola brasileira, aspectos que virão na sequência do texto.

A pedagogia crítico-emancipatória surge na Educação Física a partir dos estudos de Kunz $(1991,1994)$ e se consolida com a publicação da coletânea Didática da Educação Física, que em três volumes assoma trabalhos de outros pesquisadores que orientaram suas investigações de acordo com a mesma perspectiva teórica. Atualmente, a proposta vem "[...] sendo pesquisada, experimentada, questionada e ampliada por diversos autores e profissionais da área" (KUNZ, 2005, p.317). Boa parte das construções teórico-práticas da proposta tensiona a forma tradicionalista com que a Educação Física tematizou o conteúdo esportivo, geralmente enfatizando os objetivos atrelados ao esporte de rendimento (KUNZ, 1994). Para o autor, a permanência dessa prática não dava conta das especificidades e da finalidade da escola, já que 0 aluno a frequenta com a intenção de estudar e não de se tornar atleta. Com efeito, esse tipo de entendimento não tornava possível o desenvolvimento de competências que, para 0 autor, são fundamentais para a consecução de uma educação efetivamente emancipatória.

Em síntese, alguns pressupostos circunscrevem a compreensão da teoria. Primeiramente, o de perceber 0 aluno como um sujeito dotado de capacidades críticas suficientes para atender aos desafios complexos que o mundo apresenta. Segundo, que estes "desafios" precisam ser orientados segundo uma percepção de que cabe aos alunos (mediados pelo professor) pensarem as transformações da sociedade norteados por objetivos que ressaltem a justiça e a igualdade entre os seus integrantes. Terceiro, que a educação se desenvolve a partir da crença (do professor) no potencial crítico dos alunos sem o qual não é 
possível contemplar tal abordagem. Por fim, que a cultura de movimento se desenvolva através da Educação Física, preservando em suas práticas a capacidade crítica dos alunos e, desta forma, cultivando um ambiente propício à emancipação (KUNZ, 2005).

A concretização desses pressupostos só é possível a partir do desenvolvimento de três níveis de competências: a competência objetiva, a social e a comunicativa. A competência objetiva corresponde aos conhecimentos específicos do saber humano e na Educação Física equivale a aprender as habilidades práticas da cultura corporal de movimento. A competência social indica que é necessário aprender aspectos atrelados às relações socioculturais e sobre os papéis assumidos pelos indivíduos na sociedade no tocante aos conhecimentos da Educação Física. Para a competência comunicativa, é preciso desenvolver diversas formas de linguagem (oral, de movimento, cênica, artística, etc.), dando conta de que "[...] saber se comunicar e entender a comunicação dos outros é um processo reflexivo e desencadeia iniciativas do pensamento crítico" (KUNZ, 2005, p.318).

O processo de ensino-aprendizagem proposto pela pedagogia crítico-emancipatória concebe a organização didática de três categorias (trabalho, interação e linguagem) que, embora constituídas em separado, totalizam o esforço de desenvolver as competências anteriormente citadas. A categoria trabalho compreende as atividades de natureza prática vivenciadas pelos alunos a partir dos conhecimentos extraídos da cultura corporal de movimento. A categoria interação observa a necessidade de práticas que atendam características de uma ação cooperativa, participativa e solidária, de forma que as contradições e os conflitos possam ser resolvidos por meio de uma relação dialógica entre alunos e professores. A categoria linguagem expressa o formato em que as sistematizações dessas práticas precisam se orientar, de forma que seja possível ir além da linguagem corpórea, tradicionalmente mais usual nas aulas. Com efeito, outras linguagens podem ser utilizadas ao passo que obrigatoriamente expressem 0 pensamento dos alunos quando submetidos às práticas, assim, credita-se a esta categoria a contemplação do desenvolvimento da capacidade crítica e criadora dos alunos. Portanto, percebe-se que as categorias organizadas por Kunz (1994) tornam possível, no plano didático, que o ensino de Educação Física, ao se orientar por elas, desenvolva as competências necessárias que ensejam aos alunos uma educação emancipatória.

O início do ponto convergente entre a pedagogia crítico-emancipatória e a concepção de mídia-educação segue a compreensão de que:

[...] uma teoria no sentido crítico-emanciapatório precisa, na prática, estar acompanhada de uma didática comunicativa, porque ela deverá fundamentar a função do esclarecimento e da prevalência racional de todo o agir educacional. Assim, uma racionalidade, com o sentido do esclarecimento, implica sempre numa racionalidade comunicativa. Devemos pressupor que a educação é sempre um processo no qual se desenvolvem "ações comunicativas". (...) A capacidade comunicativa não é algo dado, simples produto da natureza, mas deve ser desenvolvida (KUNZ, 2005, p.317 - grifo nosso).

Ou seja, do ponto de vista metodológico e da transposição teórica ao campo concreto do labor docente, é fundamental não perder de vista a ação comunicativa, pois é ela que irá sustentar a possibilidade de se criar no contexto das práticas/aulas um ambiente propício ao desenvolvimento emancipatório. Em outras palavras, a atitude comunicativa infere sobre o interlocutor o esforço de sistematizar o pensamento, e ele o faz por meio da linguagem. 
natureza - tem-se a certeza de que a ele se oferece o desenvolvimento de sua capacidade rumo à criticidade. É isso que se objetiva na pedagogia crítico-emancipatória: a capacidade de tornar os indivíduos emancipados, para que consigam pensar de forma autônoma; é aí que reside uma conexão-chave desta teoria com a mídia-educação.

Segundo Belloni (2005), a mídia-educação surge no contexto das "tecnologias de informação e comunicação" (TICS). As TICs compreendem o avanço tecnológico das estruturas de comunicação, como a televisão, o rádio, o jornal, o cinema e a internet, que ao penetrarem de maneira abrupta e contundentemente em todas as instâncias da vida social, tornaram-se objeto de estudos de caráter multidisciplinar. Para a autora, as TICs agregam duas dimensões indissociáveis e que têm servido de categorias de estudo na área. É o caso da "comunicação educacional", que dirige sua atenção aos estudos de perceber o potencial da mídia como ferramenta pedagógica; e a "mídia-educação", que objetiva entender as mídias como um objeto de estudo na educação, comumente chamada de "educação para as mídias".

Os avanços no campo dos processos educacionais na área da mídia-educação, defendidos por Belloni (2005), demonstram prospectivas coincidentes no que diz respeito aos objetivos ilustrados pela pedagogia crítico-emancipatória, sobretudo no que correspondem aos papéis de professor e aluno. Nesse sentido, a autora destaca a necessidade do estabelecimento de um novo paradigma na escola para esses personagens, pois o trabalho segundo a mídiaeducação fará abrolhar o "professor coletivo e multicompetente" e o "estudante autônomo".

Sobre a formação desse "novo" professor, Belloni (2005) entende que será necessária uma ampla reforma nos currículos de licenciatura e também que os métodos de ensino na formação inicial priorizem o desenvolvimento de habilidades adquiridas pelos processos interdisciplinares e a estreita relação dos conhecimentos com as mídias. Na esteira desta mesma conclusão, Pires (2002, p.170), amparado por estudo circunscrito à pedagogia críticoemancipatória e pensando a formação do professor de Educação Física, corrobora:

\footnotetext{
A inclusão tematizada dos meios de comunicação de massa e de suas influências culturais na sociedade contemporânea, que se revela importante em relação à escola em geral e aos diferentes componentes curriculares que compõem 0 seu currículo, faz-se ainda mais relevante no ensino superior, notadamente nas instâncias formadoras de professores, condição precípua para que este profissional venha a desenvolver competência emancipatória [...]. Nesse sentido, entende-se reforçado os argumentos favoráveis à inclusão da mídia esportiva como tema específico de estudo e como eixo curricular interdisciplinar para a Educação Física [...]
}

Quanto ao aluno - que nas palavras de Belloni (2005) sugerem um estudante autônomo -, se formado nos termos da mídia-educação, desenvolverá habilidades relacionadas à autoaprendizagem e será gestor do seu próprio processo de aquisição de conhecimento. Tais aspectos se aproximam das ideias de Kunz (2005) de antemão apresentadas, principalmente na percepção de buscar, no processo de ensino-aprendizagem, ações que contribuam para 0 desenvolvimento autônomo dos sujeitos, por meio de práticas que intencionalmente valorizem o protagonismo discente.

Embora seja possível estabelecer estreitamentos teóricos entre a pedagogia críticoemancipatória e a mídia-educação, é mister registrar a constatação de como se configura essa consonância em termos concretos, ou seja, a partir de uma experiência no campo da escola. É o que se pretende destacar a seguir. 


\section{POR UM ENSINO EMANCIPATÓRIO EM EDUCAÇÃO FÍSICA: CONTRIBUIÇÕES DA MÍDIA-EDUCAÇÃO}

Só é possível pensar a aproximação entre concepção de mídia-educação e a Educação Física Escolar face ao progresso deste componente curricular na escola nos últimos trinta anos, algo anteriormente destacado. Entretanto, as características prolíficas destacadas no pensamento pedagógico da Educação Física dos últimos anos não acompanham, nos mesmos termos, os estudos que a Educação Física tem feito no processo de interface com as mídias no contexto escolar. Pires (2003) identificou essa escassez por entender a temática das mídias como uma linha de pesquisa bastante nova para a área. Em estudo mais recente, Leiro, Pires e Betti (2007) constataram o aumento significativo desses estudos, porém com pouca ênfase na proposição de práticas pedagógicas, mormente as que delimitam seu campo de estudo ao ensino de Educação Física e suas possibilidades de integração com as mídias.

De todo modo, é possível destacar algumas experiências investigativas e sobejá-las na medida em que elas apontam para resultados significativos, sobretudo no que diz respeito a uma concepção de educação emancipatória. É o caso dos estudos de Oliveira e Pires (2005) e Munarim (2007). Com a intenção de exemplificar de maneira mais contundente a questão até aqui debatida - a aproximação entre a pedagogia crítico-emancipatória e a mídia-educação -, é representativo apresentar sinteticamente os resultados do estudo de Costa (2010), na medida em que esta pesquisa demarca elementos que reforçam tal compreensão.

Costa (2010) investigou uma proposta pedagógica em Educação Física realizada numa turma de 8 ${ }^{a}$ série de uma escola privada de Brasília. Na ocasião, a proposta enfatizou o estudo da temática esportiva nas aulas, e, para além das aulas, incentivou os alunos a um exercício de pesquisa em várias modalidades, tomando como estratégia de sistematização dos resultados dessas pesquisas a produção de vídeo. No caso, a atividade de produção de vídeo direcionou algumas ações pedagógicas em torno da apropriação dos conhecimentos específicos da mídia audiovisual pelos alunos.

Desta forma, foi necessário elaborar aulas que oferecessem aos discentes assuntos que introduzissem conhecimentos acerca da tecnologia do audiovisual e sua aplicação na educação. Com efeito, levou-se adiante uma aula que tematizou as funções dos vídeos (FÉRRES, 1996), as técnicas de filmagem (plano geral, plano médio, close, câmera alta, câmera baixa, movimentos de câmera) e o uso do Movie Maker ${ }^{4}$ como editor de vídeo.

A opção didático-metodológica apresentada por Costa (2010) e experienciada na escola teve como aporte teórico a mídia-educação, sobretudo pelo fato de tomar a mídia, no caso, a produção de vídeo, como objeto de estudo no processo de ensino-aprendizagem.

A proposta pedagógica, estruturada a partir da pedagogia crítico-emancipatória, tinha ainda outros elementos importantes. Os conhecimentos acerca da cultura corporal de movimento tratados nas aulas permeavam várias modalidades esportivas não tradicionais na cultura brasileira (hóquei, Le parkour, rúgbi, polo, beisebol e críquete). Divididos em grupos de trabalho, os alunos, de forma autônoma, socializavam os conhecimentos anteriormente pesquisados sobre estas modalidades, e sugeriam formas adaptadas de prática durante as aulas. As práticas vivenciadas pelo coletivo tornaram-se mais a frente subsídio imagético para a produção de vídeos. 
Os vídeos também foram objeto de avaliação do processo de ensino-aprendizagem dos alunos. A eles também coube a tarefa de contribuir neste componente didático. Na medida em que as produções dos vídeos foram socializadas na turma, os alunos tiveram a incumbência de avaliar o produto da pesquisa de seus pares. Costa (2010) concluiu que esta diligência sinalizou para uma possível atitude crítica dos alunos quando estes foram, em algumas ocasiões, bastante rígidos na avaliação, principalmente na análise de aspectos específicos da qualidade dos vídeos.

Uma vez em que um dos objetivos da concepção de mídia-educação é o de forjar consumidores crítico de mídia, segue o entendimento de que

[...] a prática, o fazer, ou seja, a produção, traz uma dimensão concreta e pragmática para a reflexividade. [...] ao conectar suas práticas pedagógicas aos novos recursos disponíveis em termos de tecnologias audiovisuais, [...], possibilitamos também aos estudantes uma condição de produtores, além de consumidores críticos (OROFINO, 2005, p. 126).

Segundo Costa (2010), a experiência de produzir um vídeo em aulas de Educação Física, numa turma de ensino fundamental, segundo uma concepção de mídia-educação e coadunada a uma proposta pedagógica alinhavada com a pedagogia crítico-emacipatória, criou um ambiente propício ao desenvolvimento da autonomia discente, do pensamento crítico e da participação ativa dos alunos nas aulas.

Observando estes aspectos, há um entendimento que a proposta pedagógica estruturada nestes termos reforça o seguinte pensamento:

A concepção de mídia-educação perspectivada em nosso estudo favoreceu um sentido às aulas de Educação Física, que tradicionalmente não tem sido focalizado pela disciplina. Desta forma, podemos pensar que passa por um "direito" do estudante o desenvolvimento de competências que o leve a pensar autonomamente, quando, por exemplo, exercitam a reflexão sobre a cultura corporal de movimento. É "direito" do estudante desenvolver suas capacidades inquisitivas quando submetido ao exercício de uma pesquisa. Também é "direito" desenvolver suas capacidades produtivas, quando confrontado com a possibilidade de transformar 0 conhecimento com o propósito de elaborar um produto de audiovisual (COSTA, 2010, p. 134).

Logo, a opção pela concepção de mídia-educação não pode ser compreendida como mero "modismo contemporâneo" nos processos educacionais formais. Em se tratando de Educação Física, talvez o recrudescimento desta opção como metodologia didática de ensino é ainda mais difícil, observando a difusão histórica de uma concepção de ensino tradicionalista da área, baseada, ainda hoje, assaz no modelo da aptidão física. Tal constatação fortalece o entendimento de que é preciso cada vez mais elaborar e experimentar metodologias que traduzam alternativas de ensino diferentes, e que se apresentem com características reformistas.

Por outro lado, incide sobre essa experiência a dúvida se caso uma proposta pedagógica em Educação Física estruturada numa concepção de mídia-educação descaracterizaria a especificidade do próprio componente curricular naquilo que corresponde à oferta de corporeidade e da prática motora nas aulas. Sobre isso Betti (2001) alerta que há uma dificuldade da parte dos professores em aderir a uma prática pedagógica que ofereça momentos de reflexão aos alunos, por entenderem que esta opção tornaria as aulas desinteressantes. 
Contudo, para o autor, trabalhar com as mídias nas aulas de Educação Física não quer dizer torná-las "aulas teóricas", pois ao professor cabe aproximar criticamente o fenômeno midiático ante os conteúdos da Educação Física Escolar. Observando a pesquisa de Costa (2010), temos um exemplo metodológico de prática pedagógica, realizada no lócus da escola e que oferece subsídios concretos de uma experiência didática que integra elementos de mídia por meio da pedagogia crítico-emancipatória. Este fato denota aos resultados obtidos pela pesquisa elementos significativos na busca por um ensino crítico em Educação Física, e que aludiu às possibilidades emancipatórias do ensino, por meio de uma metodologia forjada segundo a concepção de mídia-educação.

\section{CONSIDERAÇÕES FINAIS}

As reflexões e a discussão da temática da Educação Física Escolar ofertada até agora explicitamente identificam na pedagogia crítico-emancipatória uma possibilidade didáticometodológica que compreende a oferta de um ensino que contribui para a fundamentação da prática pedagógica de professores de Educação Física na escola. Ademais, a concepção de mídia-educação se mostra um elemento que potencializa esses constructos didáticos, transcendendo os limites tradicionalmente impostos pelo componente curricular de Educação Física, sobretudo aqueles que o caracterizaram como mera "atividade prática". Isso não quer dizer que outras abordagens pedagógicas não se constituam como legítimas no que se refere às suas proposições metodológicas. Entretanto, o que se tentou demonstrar por meio deste ensaio é que há proximidades conceituais e de objetivos no que diz respeito às teorias pedagógicas aqui brevemente apresentadas e que se reconhece nelas o esforço de oferecer aos alunos uma educação emancipatória.

Para além dessa questão, e na medida em que se aceitam os avanços teóricos da Educação Física no que concerne à didática, se torna importante perceber que estas construções advieram em boa parte por meio de elaborações teóricas e textos ensaísticos. Urge perceber que no contexto da produção científica da área há ainda a necessidade de consolidar as teorias ou abordagens pedagógicas utilizando-se de pesquisa empírica e que tome como objeto a prática pedagógica na escola. Embora se reconheçam as características multidisciplinares da Educação Física, é irrefutável que os saberes produzidos cientificamente no tocante à questão da prática pedagógica ainda são incipientes quando comparados aos estudos na área biomédica e do treinamento esportivo. Ademais, é finalidade idiossincrática do campo escolar legitimar a instituição de direitos do coletivo da população brasileira e produzir, em seus desdobramentos, desenvolvimento e formação humana. Mesmo que tais argumentos não encontrem ressonância no pragmatismo da ordem dos estímulos a essa dimensão ou campo de pesquisa, é mister tensionar este modelo, sobe pena de, se assim não o fizer, reafirmar a percepção de que, na escola, "a teoria, na prática, é outra".

\section{REFERÊNCIAS}

ARAÚJO, Lísia Costa Gonçalves et al. Ontologia do movimento humano: teoria do "se-movimentar" humano. Pensar a Prática, Goiânia, v. 13, n. 3, p. 1-12, set/dez. 2010.

BELLONI, Maria Luíza. O que é Mídia-Educação. Campinas: Autores Associados, 2001. 
BETTI, Mauro. Mídias: aliadas ou inimigas da educação física escolar? Motriz, Rio Claro, v. 7, n. 2, p. 125-129, jul.-dez, 2001.

CARDOSO, Carlos Luiz. Unidade didática 4: concepção de aulas abertas. In: KUNZ, E. (Org.). Didática da educação física 1. ljuí: Ed. Unijuí, 1998. p. 121-158.

CASTELLANI FILHO, Lino. Política educacional e educação física. Campinas: Autores Associados, 1998.

COSTA, Jonatas Maia da. Educação Física escolar e a linguagem audiovisual: uma proposta de ação pedagógica. 173f. 2010. Dissertação (Mestrado em Educação Física) - Programa de Pósgraduação em Educação Física, Faculdade de Educação Física, UnB, Brasília, 2010.

DARIDO, Suraya. Educação Física na escola: questões e reflexões. Rio de Janeiro: Guanabara Koogan, 2003.

FALCÃO, José Luiz Cirqueira. Unidade didática 2: Capoeira. In: KUNZ, E. (Org.). Didática da educação física 1. ljuí: Ed. Unijuí, 1998. p. 55-94.

FÉRRES, Joan. Vídeo e educação. Porto Alegre: Artes Médicas, 1996.

GHIRALDELLI JR, Paulo. Educação Física progressista: a pedagogia crítico-social dos conteúdos e a educação física brasileira. São Paulo: Loyola, 1989.

HERNANDEZ, Fernando; VENTURA, Montserrat. A organização do currículo por projetos de trabalho. Porto Alegre: Artes Médicas, 1998.

HILDEBRANDT, Reiner; LAGING, Ralf. Concepções abertas no ensino de educação física. Rio de janeiro: Ao Livro Técnico, 1986.

KUNZ, Elenor. Educação Física: ensino e mudança. ljuí: Ed. Unijuí, 1991.

KUNZ, Elenor. Transformação didático-pedagógica do esporte. ljuí: Ed. Unijuí, 1994.

KUNZ, Elenor. (Org.). Didática da educação física 1. ljuí: Ed. Unijuí, 1998.

KUNZ, Elenor. (Org.). Didática da educação física 2. ljuí: Ed. Unijuí, 2002.

KUNZ, Elenor. (Org.). Didática da educação física 3: futebol. ljuí: Ed. Unijuí, 2003.

KUNZ, Elenor. Pedagogia crítico-emancipatória. In: GONZÁLES, Jaime; FENSTERSEIFER, Paulo Evaldo. (Orgs.). Dicionário crítico de educação física. ljuí: Ed Unijuí, 2005. p. 316-318.

LEIRO, Augusto Cesar Rios. PIRES, Giovani de Lorenzi. BETTI, Mauro. Notas sobre o GTT de comunicação e mídia do CBCE: história, sujeitos e desafios estratégicos. In: CARVALHO, Yara Maria. LINHALES, Meily Assbú (Orgs.). Política científica e produção de conhecimento em educação física. Goiânia: Colégio Brasileiro de Ciências do Esporte, 2007. p. $42-67$.

MATHIELLO JR., Edgard. Exercitando conhecimentos e práticas sobre meio ambiente a partir da pedagogia crítico-emancipatória. In: KUNZ, Elenor. (Org.). Didática da educação física 2. ljuí: Ed. Unijuí, 2002. p. 99-131.

OLIVEIRA, Márcio Romeu Ribas; PIRES, Giovani de Lorenzi. O primeiro olhar: experiência com imagens na educação física escolar. Revista Brasileira de Ciências do Esporte, Campinas, v. 26, n. 2, 117-133, jan. 2005

OROFINO, Maria Isabel. Mídias e mediação escolar: pedagogia dos meios, participação e visibilidade. São Paulo: Cortez, Instituto Paulo Freire, 2005.

PIRES, Giovani de Lorenzi. Educação Física e o discurso midiático: abordagem críticoemancipatória. ljuí: Ed. Unijuí, 2002.

PIRES, Giovani de Lorenzi. A Pesquisa em Educação Física e Mídia nas Ciências do Esporte: um possível estado atual da arte. Movimento. Porto Alegre, v.9, n.1, p. 9-22, 2003. 
